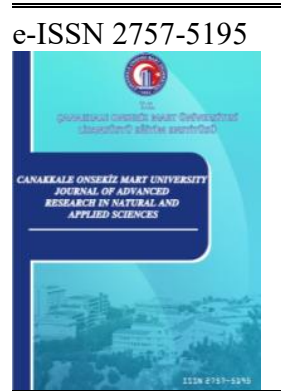

Çanakkale Onsekiz Mart University

Journal of Advanced Research in Natural and Applied Sciences

Open Access

\title{
Characterization of Asbestos in Ambient Air During Refractory Material Production from Magnesite Ore
}

\author{
Mehmet Ali Kucuker,** \\ ${ }^{1}$ Department of Environmental Engineering, Faculty of Engineering, İzmir Institute of Technology, Urla-İzmir, Turkey
}

$\begin{array}{lr}\text { Article History } \\ \text { Received: } & 12.05 .2021 \\ \text { Accepted: } & 25.08 .2021 \\ \text { Published: } & 20.09 .2021\end{array}$

Research Article

\begin{abstract}
Asbestos is a general term employed for crystallized silicate minerals in fibril form. It can be commonly found in nature and from which fibre uses in the industry through processing are obtained. However, there is limited information about the air quality in terms of asbestos for the companies that produce refractory materials from magnesite ore. This deficiency in the literature can be eliminated with this study for a company with high quality and durable refractory materials. Among the most used asbestos analysis are scanning electron microscope (SEM), transmission electron microscope (TEM). Asbestos analyses have been performed in two different institutions on the parallel samples whose preliminary processes have been completed. According to the SEM results, 23 of the observed fibrils in a total area are bigger than $5 \mu \mathrm{min}$ lengths and less than $3 \mu \mathrm{m}$ in width. Three of fibrils were observed to have the characteristics of chrysotile fibres morphemically and elementally. In addition, airborne samples were analyzed using a TEM instrument. According to the results obtained, 13 of the observed fibrils in total were bigger than $5 \mu \mathrm{m}$ in length and less than $3 \mu \mathrm{m}$ in width and based on Electron Diffraction analysis and elemental composition (EDXA) results of these fibrils, and they were not observed to have the characteristics of chrysotile fibres. Most of the observed fibrils were noted to be other inorganic minerals (lizardite) fibrils. Additionally, the obtained results show that the asbestos concentration in the air is below the limit specified by the provision $\left(0.1 \mathrm{fiber} / \mathrm{cm}^{3}\right)$.
\end{abstract}

Keywords - Asbestos, ambient air, magnesite ore, morphologic analysis

\section{Introduction}

Assessment of occupational exposure to air pollutants in workplaces has an essential place in worker health and safety programs (Melville \& Lippmann, 2001; Marioryad et al., 2011). In the last few decades, there has been a growing interest in determining the harmful effects of inorganic fibrils in the air of the working environment on human health. In addition, another concern is to find the source of these air pollutants and to minimize the exposure. One of the most dangerous inorganic fibres is asbestos group fibrils in the workplaces. Asbestos is a general term employed for crystallized silicate minerals in fibril form, commonly found in nature. From which fibre to be used in industry through processing is obtained. Its significance for the industry is that it is resistant against heat, friction, acidic, and alkaline. It has a high-tension resistance. It is dielectric, and fibrous have an elastic feature. It is vital to investigate whether such inorganic fibrils are present in the air around the working environment.

For this reason, the air quality of the working environment is constantly examined in many industrial establishments. According to the literature, it has been noticed that asbestos and its derivatives are observed in the working air of some industrial activities. However, there is limited information about the air quality in terms of asbestos for the companies that produce refractory materials from magnesite ore. In order to eliminate this deficiency in the literature, it was aimed to characterize the fibers by performing an asbestos analysis using

\footnotetext{
1 (D) mehmetalikucuker@iyte.edu.tr

${ }^{*}$ Corresponding Author
} 
SEM and TEM in the ambient air in the factory of a company that produces high quality and durable refractory materials from magnesite ore for the iron and steel industry in Turkey. Additionally, this is the first record study on the determination of the asbestos in the ambient air of the reflector material production from magnesite ore.

\subsection{Magnesite Ore and Refractory Material Production}

Magnesium ( $\mathrm{Mg})$ is an alkaline earth element and one of the most abundant elements in the earth's crust (Erdoğan and Yıldız, 1995). Due to the high affinity of the Mg to oxygen, it is coated with a matt-coloured oxide layer in the ambient air. Because of this feature, $\mathrm{MgO}$ (Magnesia), which is formed by the element $\mathrm{Mg}$ with oxygen, is used to produce refractory materials. It does not melt up to $2800{ }^{\circ} \mathrm{C}$, and it can maintain its solid structure at high temperatures (Erdoğan and Yıldız, 1995). The most important source of magnesia is magnesite $\left(\mathrm{MgCO}_{3}\right)$, a magnesium carbonate mineral. It is common in nature and theoretically contains $52.3 \%$ $\mathrm{CO}_{2}, 47.7 \% \mathrm{MgO}$ and a limited amount of $\mathrm{Fe}_{2} \mathrm{O}_{3}$; its hardness is between 3.4 and 4.5. It is a mineral with a specific gravity of 2.9-3.1 (Erdoğan and Y1ldız, 1995). Sinter magnesite is produced from magnesite ore to be used in quality and durable refractory materials, mainly for the iron and steel industry.

\subsection{Asbestos Effects on Human Health}

According to the World Health Organization, approximately 125 million people are exposed to asbestos at workplaces worldwide (WHO, 2007). It can result in asbestos-related diseases such as lung cancer, mesothelioma, or asbestosis (Park, 2018). Several factors are listed as an asbestos concentration in the ambient air, the exposure time, size and type of the fibers, functional and anatomical conditions of exposed employers, and the respiratory rate associated with physical exertion for the health hazard of asbestos (Rodilla et al., 2021). The previous studies figure out the most significant risk exists with exposure to amphibole fibers, followed by mixed fibers (amphibole and chrysotile), and finally, chrysotile (Rodilla et al., 2021). In addition, the risk of asbestos in the air bases on the type of asbestos, the physicochemical characteristics of these fibers, the intensity of exposure and, for some pathologies, co-exposures with other carcinogens (Rodilla et al., 2021). Therefore, these factors should be considered while measuring the asbestos health effects. On the other hand, the governments or unions have been lovered the exposure limit values in order to protect workers' health year by year.

\subsection{Regulations Regarding to Asbestos}

When the European Union (EU) regulations are examined, there are primarily two European Union Directives concerning asbestos. The first regulation is the European Union Directive 83/477/EEC covering the measures intended for work health and safety in workplaces where asbestos or asbestos-related materials are used (EU, 1983). The existing member country legislation designed to protect workers against asbestos in European Union countries have been prepared upon considering European Union Directive 83:477:EEC dated 19 September 1983 (EU, 1983). To strengthen the "controlled use" regime, council directives 91/383/EEC dated 25.06.1991 (EU, 1991), 2003/18/EEC dated 27.03.2003 (EU, 2003) and 2009/148/EC dated 30.11.2009 (EU, 2009) that prescribes amendments in the said directive have been issued and adapted. Some of those amendments have allowed the safe use of asbestos products by following specific procedures. The second one is the European Union Directive 76/769/EEC (EU, 1976) covering the provisions regarding asbestos use and marketing. Regulations regarding asbestos in Turkey can be listed as follows:

- "Guidelines Regarding the Measures to be Taken Inflammable, Explosive, Hazardous and Harmful Works and Workplaces" was adopted pursuant to the article 74 of Labor Law number 1475 and was published on the Official Gazette 14752 dated 24.12.1973 (APTSR, 2005).

- "Regulations on Controlling Harmful, Hazardous Substances and Products" adopted by Environmental Ministry that was published on Official Gazette number 21634 dated 11.07.1993 as well as the regulations which prescribed amendments in the laws (APTSR, 2005). 
- "Regulations on Health and Safety Measures Intended for Workers Working with Asbestos" adopted according to article 30 of Labor Law number 6331 and which was published on Official Gazette number 28539 on 25.01.2013. According to article 11 of those regulations, the provision stating "Employer shall make sure that eight hours time-weighted average (ZAOD-TWA) value of asbestos concentration in the air to which the workers are subjected shall not exceed 0,1 fiber/ $/ \mathrm{cm}^{3 "}$ is valid (ACSGOHY, 2013).

- "Regulation on Restriction and Prohibition of Hazardous Substances and Mixtures" which is intended for the prohibition of the manufacture and use of asbestos that is causing cancer as well as the marketing of asbestos-containing goods and that was published in Official Gazette number 29182 dated 21.11.2014 (ZMKKYHY, 2014) has been reissued upon taking into consideration of the 17th attachment regarding the limitations on the Registration, Evaluation, Authorization and Restriction of Chemicals Regulations regarding the Registration, Evaluation, Permission and Limitation of Chemicals pursuant to the European Union Parliament and Council number 1907/2006/EC (EU, 2006) and was published on the Official Gazette number 27687 dated 29 August 2010. Thus, reissued regulations have entered into force as of 31 December 2010. According to the third paragraph of (A) section under the heading "1. Provisions regarding Asbestos" in the Attachment 1 of the Regulations it is stated that "Chrysotile asbestos (white asbestos) fibers cannot be extracted, manufactured, used in the manufacture of any other products or for any other purposes, and cannot be marketed with the intention of sale or use" (ZMKKYHY, 2014).

\section{Materials and Methods}

In determining the method, the sample type to be analyzed and the analysis device used are considered essential matters. Among the most commonly used devices in asbestos measurement are scanning electron microscope (SEM) and transmission electron microscope (TEM). Boğaziçi University Environmental Sciences Institute performed sampling from ambient air through using ISO 14966 "Ambient air — Determination of numerical concentration of inorganic fibrous particles - Scanning electron microscopy (SEM) method" and asbestos analysis has been conducted with SEM instrument consistent with the said method (ISO 14966, 2002). Asbestos analysis in the samples obtained from ambient air has been performed in accordance with ISO 13794 "Ambient air - Determination of asbestos fibres - Indirect-transfer transmission electron microscopy (TEM) method" by RJ Lee Group in the USA through using a TEM instrument as well (ISO 13794, 1999).

\subsection{Sampling}

Sampling from ambient air for asbestos analysis was performed to simulate the exposure of workers to the dust caused by asbestos or asbestos-containing materials. The opinions of the workers and representatives were taken while obtaining samples, and the sampling points were determined in line with such opinions. Four airborne sampling points were chosen: i) pre-treatment and size reduction plant; ii) despatch area; iii) production plant; and $i v$ ) storage yard. Air samples for determining the asbestos rate in ambient air were taken using three-piece disposable special filters (capillary-pore polycarbonate filter) in $25 \mathrm{~mm}$ diameter and having $0.8 \mu \mathrm{m}$ pore size upon taking into consideration the 8 hours work shift. Sample taking filters have been placed on filter fixers adjustable to 1.5 meters from the ground (Figure 1), and sampling has been performed for 8 hours at the flow rate of $8 \mathrm{~L} / \mathrm{min}$ by the flow rate adjustable vacuum pump. Two parallel samples and a total of 8 samples were taken for minimizing test shortcomings. 


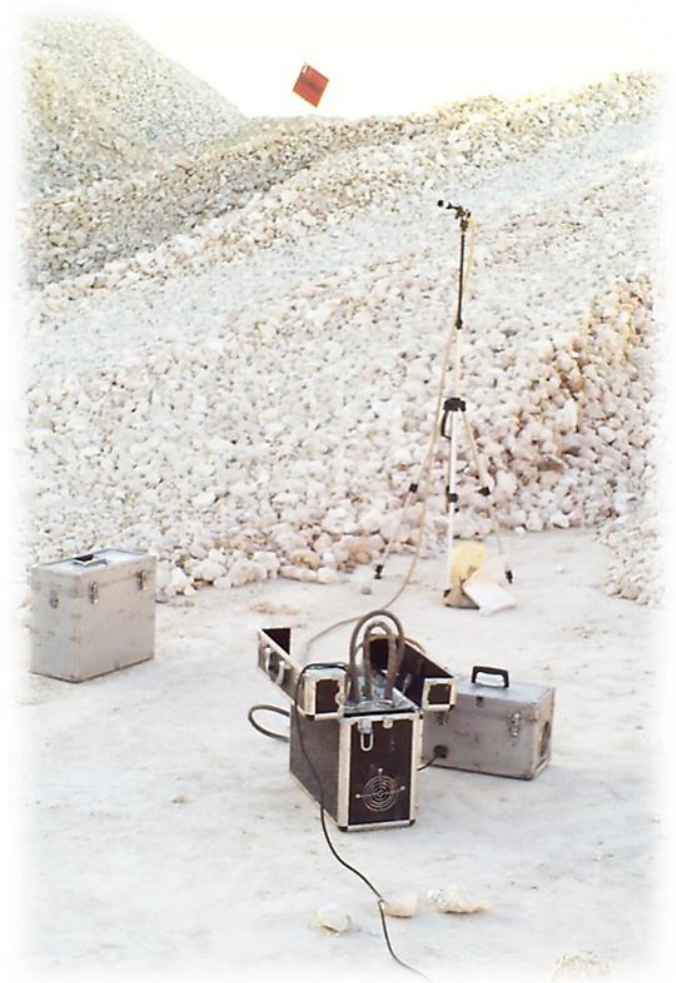

Figure 1. Sampling from ambient air in the stockyard

\subsection{Preparation of Samples for Analysis}

Obtained samples from ambient air have been sent to the US accredited RJ Lee laboratories, where they have been taken to a preliminary process. The samples were kept at $480{ }^{\circ} \mathrm{C}$ temperature for 6 hours through plasma asher by RJ Lee and thus, water and inflammable substances were eliminated in the filter. After ashing, the filter was rid of acid and soluble substances by being cleaned with 30\% diluted hydrochloric acid (HCI). Sample preparation includes ashing and dispersion of the collected particles. Thanks to these processes, all asbestos that had entered the material particles or particle agglomerates were measured. The pre-treated ambient air sample was divided into two equal parts in RJ Lee laboratories. The first part was analyzed at Boğaziçi University - Advanced Technologies Central Laboratories, the second part was analyzed in RJ Lee Group Laboratories. Parallel samples have been used in each analysis.

\subsection{Asbestos Analysis Using SEM Instrument}

Determination of the type of inorganic fibrils in the ambient air and their numerical concentration were performed at Boğaziçi University laboratory according to ISO 14966 method and by using SEM. In this method, fibers whose length is more than 5 microns and width is less than 3 microns, and with a size 3 times more than the width have been taken into consideration. During the analysis accelerating voltage of the scanning electron microscope (SEM) was adjusted as $20 \mathrm{kV}$. The scanning process of the sample was performed at the magnification in the rate of $2000 \mathrm{X}$ and $20000 \mathrm{X}$ depending on the observed fibril sizes. In the analysis performed according to the ISO 14966 method with SEM, the detection limit was determined as 300 fiber $/ \mathrm{m}^{3}$ on the scanning area of $1 \mathrm{~mm}^{2}$ filter (ISO 14966, 2002). Approximately an area of $1 \mathrm{~mm}^{2}$ has been scanned on the filter, and the fibril concentration of counted fibrils has been determined by using the formula (Equation 2.1) given below (ISO 14966, 2002). Since the pre-treated sample was divided into three parts, the result was multiplied by the verification factor. Verification factor was found through the multiplication of the rate remaining from the sample, which was subject to preliminary process and the parts of samples allocated for laboratories and then dividing the same by the dilution factor. Chemical compositions 
(elemental analysis) of the observed fibrils through energy dispersive X-rays analysis (EDXA) were determined and classified as asbestos fibrils, calcium sulphate fibrils, and other inorganic fibrils.

Fibril Concentration $(\mathrm{f} / \mathrm{ml})=\frac{\text { Number of Counted Fibrils }}{\text { Analyzed Area }\left(\mathrm{mm}^{2}\right)} x \frac{\text { Filter Area }\left(\mathrm{mm}^{2}\right)}{\text { Vacumed Air Amount }(\mathrm{ml})} x$ Verification Factor

\subsection{Asbestos Analysis using TEM Instrument}

Determination of types and numerical concentration of inorganic fibrils present in the ambient air according to ISO 13794 method by using a transmission electron microscope (TEM) were performed by RJ Lee Group laboratories in the USA. TEM sample grids were examined in low and high magnification powers and quantitative fibril count were performed in the randomly selected grid openings. The lowest detection limit for the scanned area of TEM samples is checked by total suspended particles concentration after ashing and watery phase distribution processes. This depends on the chemical properties of the dispersed particles (ISO 13794, 1999). The atmosphere whose total suspended particle concentration is approximately $10 \mu \mathrm{g} / \mathrm{m}^{3}$ is equivalent to a clear countryside atmosphere. If it is assumed that 4000 liters of the air have been filtered, an analytical accuracy of 0.5 structure/L is reached. And the examined area of $0.195 \mathrm{~mm}^{2}$ in TEM samples is equivalent to the detection limit of 1.8 structure/L (ISO 13794, 1999). The fibril concentration of the counted fibrils has been determined by using the equation 2.1. Since the obtained sample were divided into three parts, the result was multiplied by verification factor. Verification factor is found through multiplication of the rate remaining from the sample which was subject to preliminary process and the parts of samples allocated for laboratories and then dividing the same by the dilution factor.

In TEM analysis, electron diffraction (ED) was used to examine the crystal property of fiber, and energydispersive X-ray analysis (EDXA) was used to determine the elemental composition. Fiber classification process, order and morphological examination of fiber are based on electron diffraction pattern in a specific area and the qualitative and quantitative energy dispersive X-ray analysis. Identification and verification of chrysolite were only performed by quantitative ED, whereas the identification and validation of amphibole were performed by quantitative EDXA and quantitative zone axis ED (Atabey, 2009). Fiber classification was also performed.

\subsection{Classification of the Observed Fibers}

Asbestos analyses are being performed by using different instruments. In this study, the same samples have been analyzed using appropriate standard methods in other analysis devices, and the differences have been presented.

\subsubsection{Morphological Classification}

The observed fibers are separated into two classes: tube-shaped and non tube-shaped in terms of their morphological structures (Deer et al., 2009). Electron Diffraction (ED) is an electron microscope technique where the crystal feature of the sample is examined. Each fiber is further analysed by using energy dispersive $\mathrm{X}$-ray analysis (EDXA) techniques. The following methods should be used when fibers are examined through ED and EDXA techniques (ISO 13794, 1999; Rees et al., 2001; Deer et al., 2009). Crystal properties of some mineral fiber such as chrysotile are easily damaged due to the high current density required for EDXA examinations. For this reason, ED examination should be completed before the EDXA spectrums of such fibers are taken. In the examination of more stable fibers such as amphibole ED or EDXA may be used in the same priority (Deer et al., 2009).

ED technique may be qualitative or quantitative. TEM device and ED technique are used for asbestos analyses. Qualitative ED involves visual inspection of the general characteristics of ED design achieved from a randomly directed fiber on a TEM monitor screen without detailed measurements (Deer et al., 2009). ED patterns 
obtained from such fibers with cylindrical symmetry as chrysolite do not change when they are bent around their axis, and the patterns obtained from randomly directed fibers of such minerals can be interpreted quantitatively. For lizardite that does not have cylindrical symmetry, if the fiber is only directed towards the main crystallographic axis which runs parallel to the electron beam, then the ED patterns thus obtained can be interpreted quantitatively (Deer et al., 2009). Structural demonstration of standard chrysotile, lizardite and antigorite fibrils are shown in Figure 2.
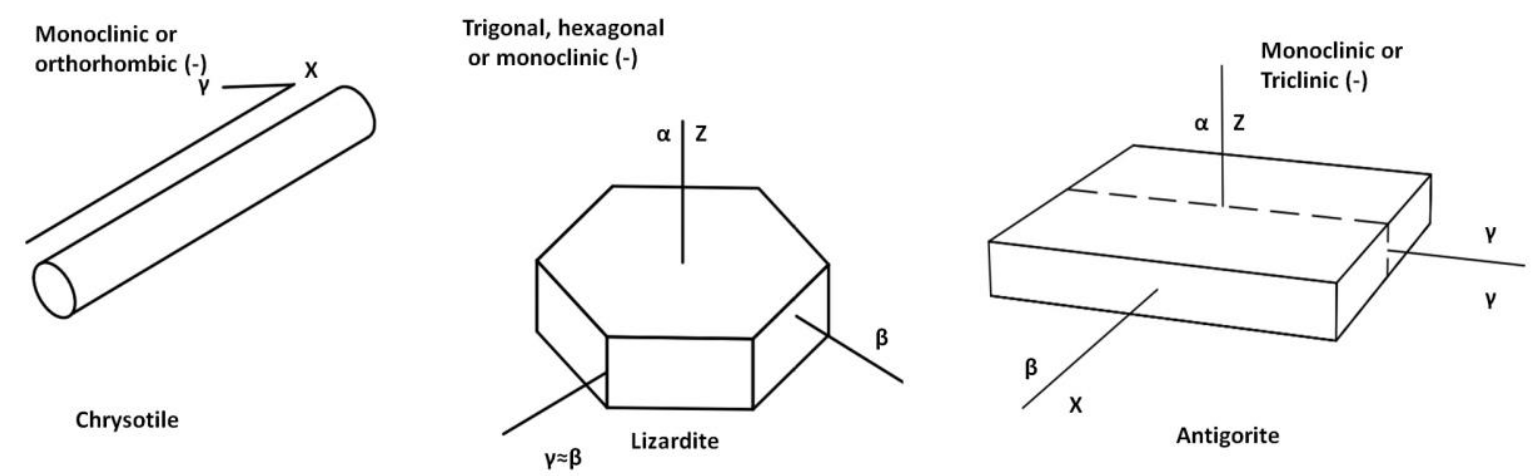

Figure 2. Structural forms of chrysotile, lizardite and antigorite fibers (adopted and redrawn from Deer et al., 2009).

\subsubsection{Classification According to Elemental Composition}

Interpretation of EDXA spectrum can be qualitative or quantitative. For qualitative interpretation of a spectrum, the peaks of $\mathrm{X}$ rays resulting from elements inside the fiber are recorded. For a quantitative interpretation, after the ground extraction has been made, clear peak areas are obtained out of X-ray peaks resulting from the elements inside fibers. This method allows a quantitative interpretation to be made for mineral containing silicium as well (Cossette \& Delvaux, 1979). In order to obtain an EDXA spectrum, the view of a fiber is moved towards the center of the screen, and the objective gap is zoomed out. An appropriate electron beam diameter is selected, and it is turned in a way as to collide into fiber beam. Depending on the device, it may be necessary to bend the sample towards the X-ray detector. It may be required to use Scanning Transmission Electron Microscope (STEM) process type in some devices. The time required to obtain a suitable spectrum varies based on fiber diameter and factors regarding the device (ASTM, 2002). For a quantitative interpretation, a statistically valid number of counts should be present for each peak. The analyses of sodium-containing fibers with small diameters are critical because such fibers are located in the lowest energy range for which the X-ray detector is less sensitive. In order to detect the existence of sodium in such fibers, the spectrum should be taken in a sufficiently long time period (Cossette \& Delvaux, 1979). The data obtained from the EDXA analyses the observed fibrils in SEM and TEM analyses. The Chrysolite, Amosite, Crocidolite, Anthophyllite, Tremolite and Actinolite values (\%) prepared based on reference asbestos minerals in Table 1 have been taken from ISO 14966 standard method (ISO 14966, 2002). The elemental composition values for lizardite have been quoted from "Rock-forming minerals: Layered silicates excluding micas and clay minerals" and thus included in Table 1 (ISO 14966, 2002; Deer et al., 2009). 
Table 1

Elemental data of asbestos fibrils (ISO 14966, 2002; Deer et al., 2009).

\begin{tabular}{l|ccccccc}
\hline & Chrysotile & Amosite & Crocidolite & Antophylite & Tremolite & Actinolite & Lizardite \\
\hline $\mathbf{S i O}_{2}(\%)$ & 36 to 44 & 49 to 53 & 49 to 56 & 53 to 60 & 55 to 60 & 51 to 56 & 39 to 42 \\
$\mathbf{M g O}(\%)$ & 38 to 42 & 1 to 7 & 0 to 3 & 17 to 34 & 20 to 26 & 12 to 20 & 39 to 43 \\
$\mathbf{F e O}(\%)$ & 0 to 3 & 34 to 44 & 13 to 21 & 0 to 20 & 0 to 5 & 5 to 15 & 0 to 2 \\
$\mathbf{F e}_{2} \mathbf{O}_{3}(\%)$ & 0 to 5 & 0 to 5 & 13 to 20 & 0 to 5 & 0 to 5 & 0 to 5 & 0 to 3 \\
$\mathbf{A l}_{2} \mathbf{O} 3(\%)$ & 0 to 2 & 0 to 1 & 0 to 1 & 0 to 3 & 0 to 3 & 0 to 3 & 0 to 1 \\
$\mathbf{C a O}(\%)$ & 0 to 2 & 0 to 2 & 0 to 3 & 0 to 3 & 10 to 15 & 10 to 13 & 0 to 1 \\
$\mathbf{K}_{2} \mathbf{O}(\%)$ & 0 to 1 & 0 to 1 & 0 to 1 & 0 to 1 & 0 to 1 & 0 to 1 & 0 to 1 \\
$\mathbf{N a}_{2} \mathbf{O}(\%)$ & 0 to 1 & 0 to 1 & 4 to 9 & 0 to 1 & 0 to 2 & 0 to 2 & 0 to 1 \\
$\mathbf{H}_{2} \mathbf{O}(\%)$ & 12 to 14 & 2 to 5 & 2 to 5 & 1 to 6 & 1 to 3 & 1 to 3 & 12 to 13 \\
\hline
\end{tabular}

In the interpretation of fibril analysis, chrysolite's morphological structure is characteristic and can be easily understood through experience. However, a few minerals with similar appearance and morphological observation are insufficient for most samples (ISO 13794, 1999). If the determined characteristics of the pattern correspond to those obtained from reference chrysolite, then the ED pattern obtained from chrysolite is highly characteristic of that mineral. However, the crystal property of fiber could be damaged due to various factors, and it may not provide an ED pattern. In that case, elemental composition (EDXA spectrum) could be the only relevant data added to the morphological observation (ISO 13794, 1999).

\section{Results and Discussion}

\subsection{Analysis of Ambient Air Samples Using SEM}

The samples collected from ambient air were analyzed using a scanning electron microscope (SEM) at the Advanced Technologies R\&D Central Laboratory of Boğaziçi University. The methods obtained were evaluated considering the chemical and structural (morphological) characteristics of the asbestos fibers as contained in methods and reference books. The analyses conducted with an SEM instrument on 2 parallel samples (Airborne 1 and Airborne 2) collected from ambient air are summarized in Table 2. Figure 3 shows the 3 chrysotile fibrils observed by the analyses. Chrysotile fibrils of the samples collected from ambient air are shown together with EDXA results. Figure 4 shows example images of another inorganic mineral (lizardite) fibrils observed by the analysis of ambient air.

Table 2

SEM analysis results of the samples collected from ambient air

\begin{tabular}{|c|c|c|c|c|c|c|}
\hline \multirow{2}{*}{$\begin{array}{l}\text { Sample } \\
\text { Code }\end{array}$} & \multirow[t]{2}{*}{ Verification } & \multirow{2}{*}{$\begin{array}{l}\text { Analyzed } \\
\text { Area, } \mathrm{mm}^{2}\end{array}$} & \multicolumn{2}{|c|}{$\begin{array}{c}\text { Number of Fibrils } \\
\text { Observed }\end{array}$} & \multicolumn{2}{|c|}{ Asbestos Concentration * } \\
\hline & & & Chrysotile & Other & $\mathrm{s} / \mathrm{mm}^{2}$ & $\mathrm{~s} / \mathrm{ml}$ \\
\hline Airborne 1 & 0.7666 & 1 & 1 & $80(13)$ & $<0.76$ & $<0.00001$ \\
\hline Airborne 2 & 0.7965 & 1 & 2 & $75(10)$ & $<1.6$ & $<0.00004$ \\
\hline
\end{tabular}

In light of the data obtained, the observed fibrils were analyzed both morphologically and elementally. The tubular shape, which is the morphologic structure of the chrysotile, was determined in the fibrils observed as a result of the analysis. 
In the elemental compositions obtained as a result of the EDXA analyses of the chrysotile fibers, the percentage of $\mathrm{SiO}_{2}$ is observed to be between 40 and 44, and the ratio of $\mathrm{MgO}$ is observed to be between 38 and 42 . These values match the elemental data of the chrysotile fibers as given in Table 1.

Other inorganic mineral (lizardite) fibers were found among the fibrils observed by the analyses conducted with an SEM instrument on the samples collected from ambient air. The lizardite fibrils observed as a result of the investigation were determined to have a morphologically planar (flat) and stringy structure. In the elemental compositions obtained due to the EDXA analyses of other inorganic mineral (lizardite) fibers, the percentage of $\mathrm{SiO}_{2}$ is observed to be between 39 and 42, and the percentage of $\mathrm{MgO}$ is observed to be between 39 and 43. These values match the elemental data of the lizardite fibers as given in Table 1.

According to the Labor Law number 6331 and which was published on Official Gazette number 28539 on 25.01.2013 and article 11 of that regulations, the provision stating "Employer shall make sure that eight hours time-weighted average (ZAOD-TWA) value of asbestos concentration in the air to which the workers are subjected shall not exceed $0,1 \mathrm{fiber} / \mathrm{cm}^{3 "}$ is valid (ACSGOHY, 2013). The obtained results $\left(0.00004 \mathrm{fiber} / \mathrm{cm}^{3}\right)$ show that the asbestos concentration in the air is below the limit specified by the provision $\left(0.1 \mathrm{fiber} / \mathrm{cm}^{3}\right)$.

Since the equipment required to examine the crystal structure of the observed fibrils is not available in the SEM device, the crystal structures of the fibers could not be examined. For this reason, it is not sufficient to use the SEM device alone in such analyses. 

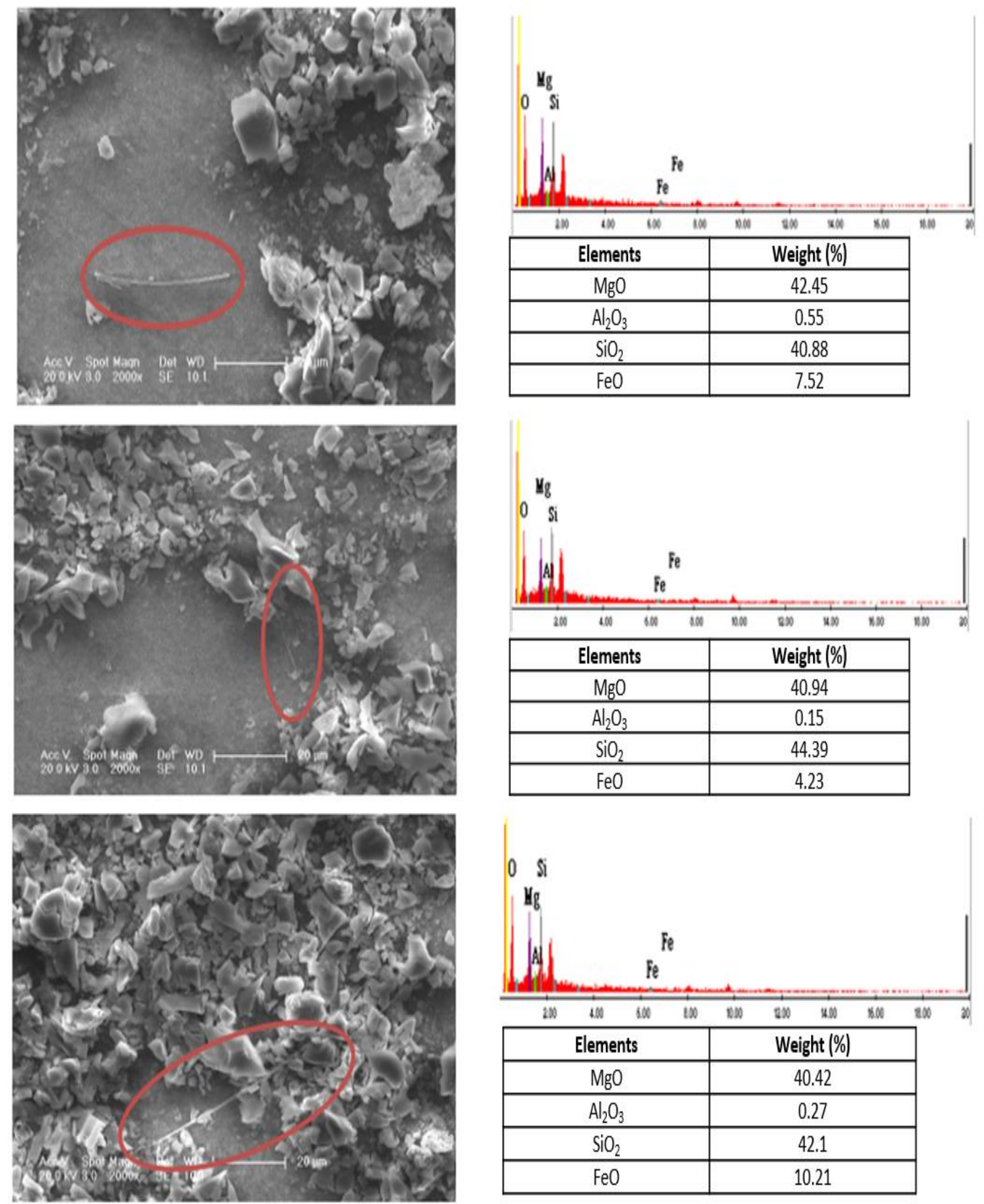

\begin{tabular}{|c|c|}
\hline Elements & Weight (\%) \\
\hline $\mathrm{MgO}$ & 40.94 \\
\hline $\mathrm{Al}_{2} \mathrm{O}_{3}$ & 0.15 \\
\hline $\mathrm{SiO}_{2}$ & 44.39 \\
\hline $\mathrm{FeO}$ & 4.23 \\
\hline
\end{tabular}

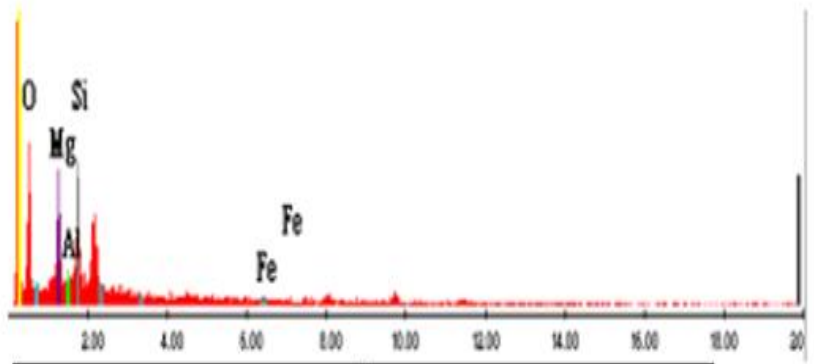

\begin{tabular}{|c|c|}
\hline Elements & Weight (\%) \\
\hline $\mathrm{MgO}$ & 40.42 \\
\hline $\mathrm{Al}_{2} \mathrm{O}_{3}$ & 0.27 \\
\hline $\mathrm{SiO}_{2}$ & 42.1 \\
\hline $\mathrm{FeO}$ & 10.21 \\
\hline
\end{tabular}

Figure 3. Chrysotile fibrils were observed in ambient air and their elemental analysis results. 

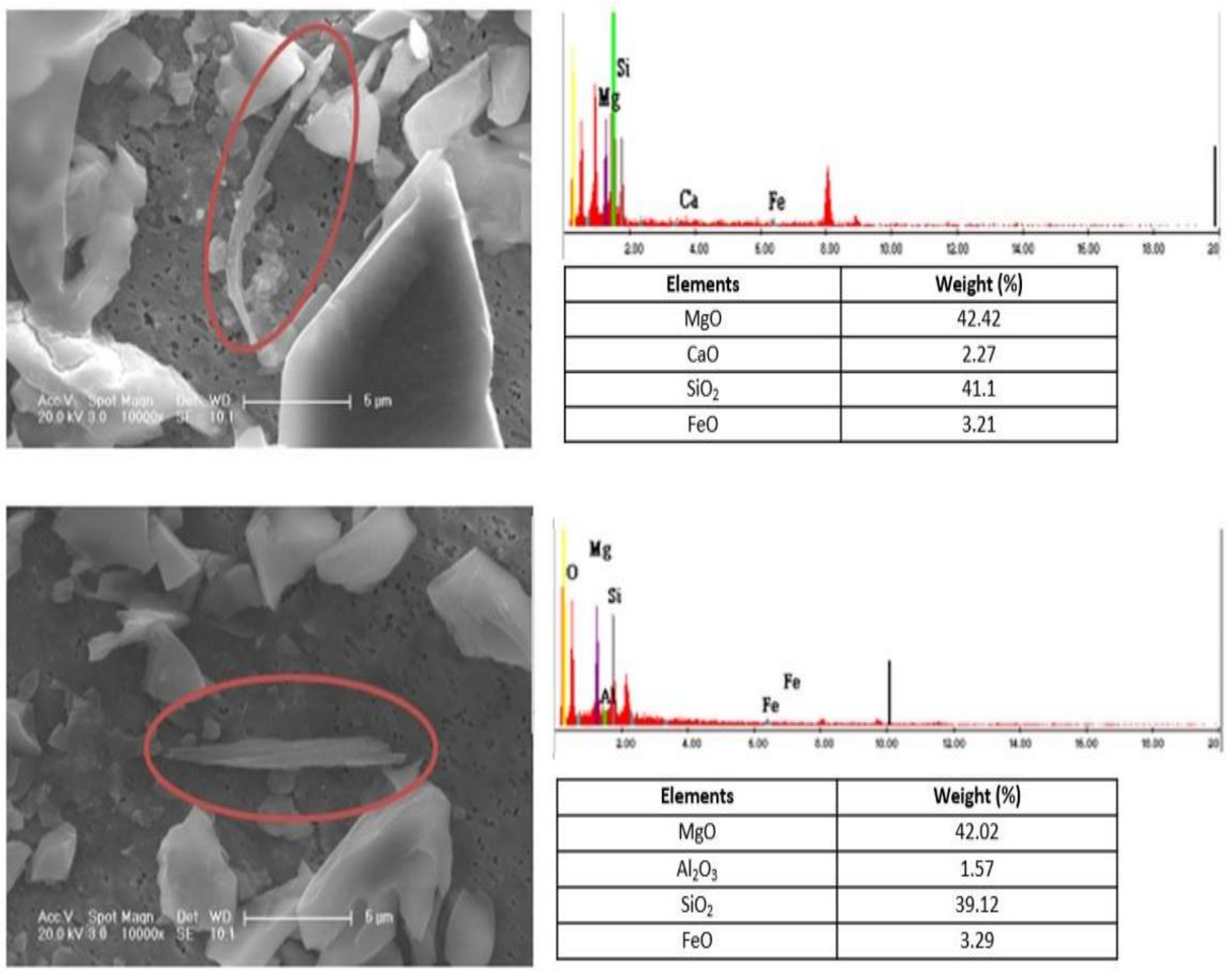

\begin{tabular}{|c|c|}
\hline Elements & Weight (\%) \\
\hline $\mathrm{MgO}$ & 42.02 \\
\hline $\mathrm{Al}_{2} \mathrm{O}_{3}$ & 1.57 \\
\hline $\mathrm{SiO}_{2}$ & 39.12 \\
\hline $\mathrm{FeO}$ & 3.29 \\
\hline
\end{tabular}
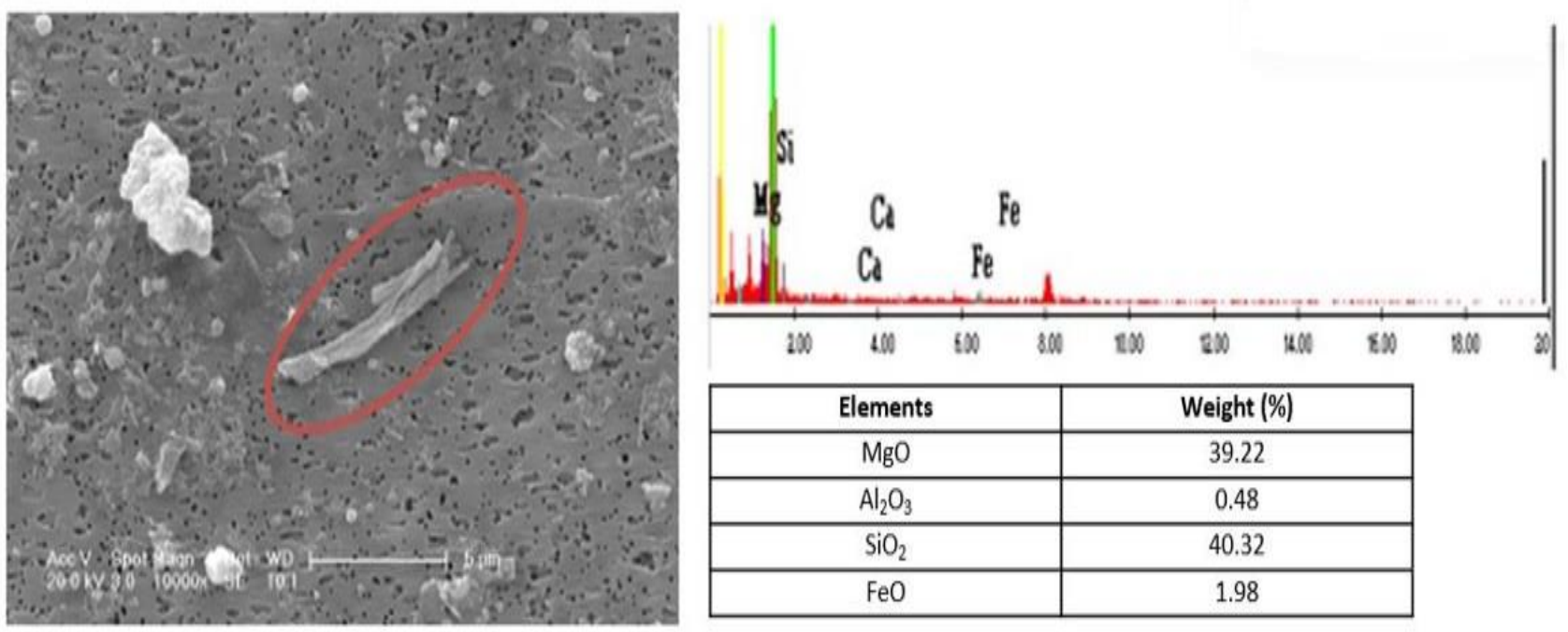

\begin{tabular}{|c|c|}
\hline Elements & Weight (\%) \\
\hline $\mathrm{MgO}$ & 39.22 \\
\hline $\mathrm{Al}_{2} \mathrm{O}_{3}$ & 0.48 \\
\hline $\mathrm{SiO}_{2}$ & 40.32 \\
\hline $\mathrm{FeO}$ & 1.98 \\
\hline
\end{tabular}

Figure 4. Other inorganic minerals (lizardite) fibrils were observed in ambient air and their elemental analysis results. 


\subsection{Analysis of Ambient Air Samples Using TEM}

The samples collected from ambient air were analyzed with a transmission electron microscope (TEM) at RJ Lee Group Laboratory in the USA. The methods obtained were evaluated considering the chemical and structural (morphological) characteristics of the asbestos fibers as contained in methods and reference books. According to the TEM analysis results obtained from the samples collected from ambient air (Airborne 1 and Airborne 2), Chrysotile fibril was not observed as a result of the analysis. The detected fibrils were indicated to be other mineral (lizardite) fibrils. Results of the samples collected from ambient air analyzed using TEM are summarized in Table 3.

Table 3

TEM analysis results of the samples collected from ambient air

\begin{tabular}{ccccccr}
\hline \multirow{2}{*}{ Sample Code } & $\begin{array}{l}\text { Verification } \\
\text { Coefficient }\end{array}$ & $\begin{array}{l}\text { Analyzed } \\
\text { Area, mm }\end{array}$ & \multicolumn{2}{c}{$\begin{array}{c}\text { Number of Fibrils } \\
\text { Observed }\end{array}$} & \multicolumn{2}{c}{ Asbestos Concentration * } \\
\cline { 4 - 7 } & & & Chrysotile & Other & $\mathrm{s} / \mathrm{mm}^{2}$ & $\mathrm{~s} / \mathrm{ml}$ \\
\hline Airborne 1 & 4.089 & 0.09243 & 0 & $53(2)$ & $<44.2$ & $<0.0044$ \\
Airborne 2 & 3.426 & 0.18504 & 0 & $102(11)$ & $<18.5$ & $<0.0019$ \\
\hline
\end{tabular}

* Concentration calculation was made according to the conditions of the sample received

" $<$ " indicates that the concentration is lower than the determination limit

"()" indicates the number of the fibrils bigger than $5 \mu \mathrm{m}$.

According to EDXA analyses of the obtained fibrils, they were observed to be consistent with the spectrums of chrysotile and antigorite among the serpentine group minerals. In addition, the fibers are understood to have a magnesium silicate structure. Examples of the observed serpentine structures on Airborne 1 and Airborne 2 are shown in Figure 5. According to the results obtained, 13 of the fibrils observed as a result of the analysis in total were bigger than $5 \mu \mathrm{m}$ in length and less than $3 \mu \mathrm{m}$ in width and based on ED analysis and elemental composition (EDXA) results of these fibrils, and they were observed not to have the characteristics of chrysotile fibers. The majority of the observed fibrils were noted to be other inorganic minerals (lizardite) fibrils.
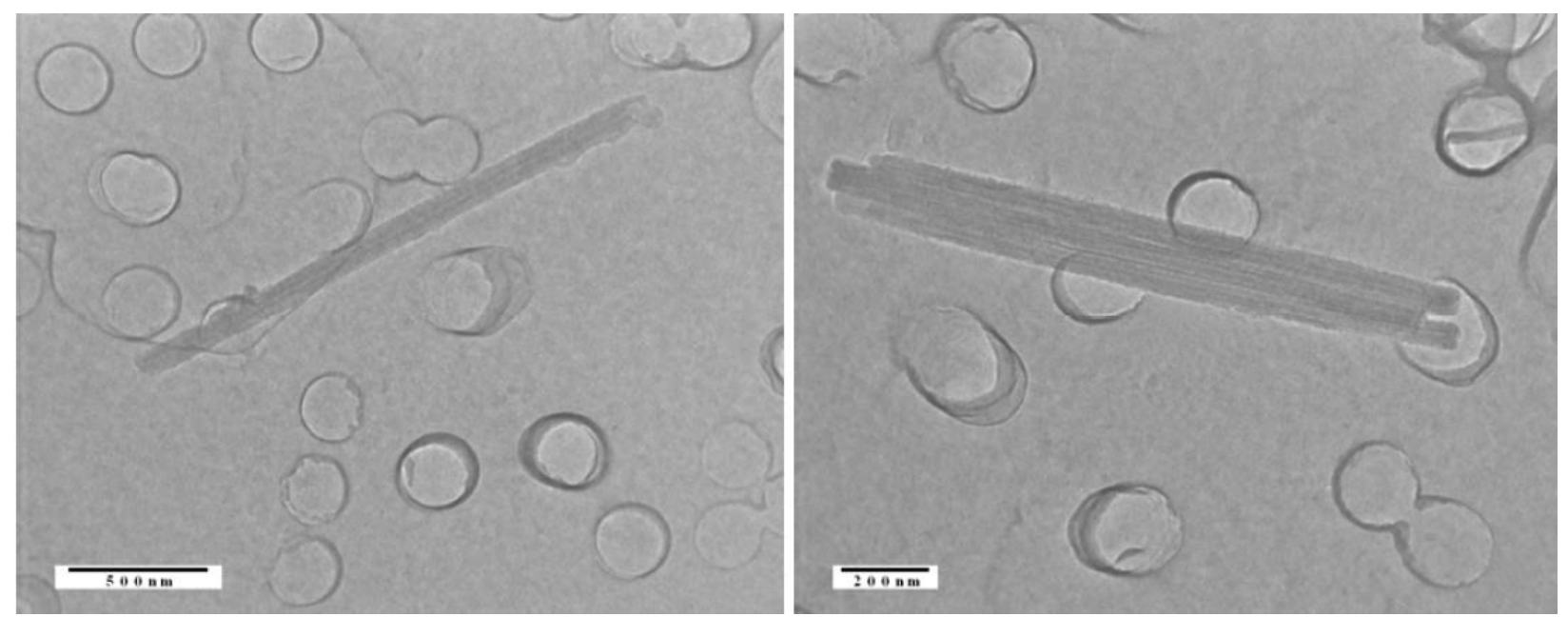

Figure 5. Typical serpentine structures were observed on samples.

Analyses with the TEM device give more reliable results in determining the types of fibrils observed. The most striking result of this study is that it is not correct to decide on the determination of asbestos types based on a single method or analysis device. The fibers should be determined by using appropriate methods and analysis devices with advanced image properties according to the sample type in such studies. On the other hand, since the detection limits of the SEM and TEM devices are different, it can be thought that the difference between the concentrations is related to this. 


\section{Conclusion}

Asbestos analysis was conducted on the samples obtained from ambient air using the SEM instrument at both Boğaziçi University Central Laboratory and RJ KLee Group. According to the results of the analyses conducted by Boğaziçi University, 23 of the fibrils observed in total are consistent with the phrase "bigger than $5 \mu \mathrm{min}$ lengths and less than $3 \mu \mathrm{m}$ in width", as set out in the "Regulation on Health and Safety Measures for Those Working with Asbestos". 3 of these fibrils were observed to have the characteristics of chrysotile fibers morphemically and elementally. Airborne samples were analyzed RJ Lee Group using TEM instrument as well. According to the results obtained, 13 of the observed fibrils in total were bigger than $5 \mu \mathrm{m}$ in length and less than $3 \mu \mathrm{m}$ in width and based on ED analysis and elemental composition (EDXA) results of these fibrils; they were observed not to have the characteristics of chrysotile fibers. Majority of the observed fibrils were noted to be other inorganic mineral (lizardite) fibrils. As a result of the asbestos analysis carried out on ambient air samples by SEM device according to the method no ISO 14966 by Boğaziçi University, asbestos concentration was found as $0.00004 \mathrm{fibre} / \mathrm{cm}^{3}$. RJ Lee Group carried out concurrent analyses according to ISO 13974 method by TEM. According to the analysis results obtained from the TEM device, asbestos concentration was 0.0004 fibre $/ \mathrm{cm}^{3}$. All of these values are below the detection limit of the relevant analysis devices. Furthermore, they are below the limit specified by the provision "The employer shall ensure that 8-hour weighted average value (TWA) of the asbestos concentration in the air the workers are exposed to will not exceed 0.1 fibre/ $\mathrm{cm}^{3}$ " according to article 11 of The Regulation on Health and Safety Precautions in Those Working with Asbestos published in the Official Gazette dated 25.01.2013 and 28539 in force. In addition, the most significant result of this study is that it is not appropriate to make a decision on the determination of asbestos types based on a single method or analysis device.

\section{Acknowledgement}

The author wishes to thank Prof. Dr. Turgut T. Onay for the support.

\section{Author Contributions}

Mehmet Ali Kucuker: Conceptualization, Methodology, Validation, Investigation, Resources, Writing, Visualization.

\section{Conflicts of Interest}

The author declares no conflict of interest.

\section{References}

ACSGOHY, (2013). Regulations on Health and Safety Measures Intended for Workers Working with Asbestos, Official Gazette Official Journal number 28539 on 25.01.2013, Ankara. Retrieved from: https://www.mevzuat.gov.tr/mevzuat?MevzuatNo=17050\&MevzuatTur=7\&MevzuatTertip=5

APTSR, (2005). Asbest veya Asbestli Malzeme ile Üretim Yapılan İsyerlerinde İs Sağllğ ve Güvenliği Proje Denetimi Sonuç Raporu, T.C. Çalışma ve Sosyal Güvenlik Bakanlığı İş Teftiş Kurulu Başkanlığı, Ankara. Retrieved from: https://ailevecalisma.gov.tr/medias/5974/2005 01.pdf

ASTM, (2002). "Standard Test Method for Microvacuum Sampling and Indirect Analysis of Dust by Transmission Electron Microscopy for Asbestos Mass Concentration", ASTM D5756, American Society for Testing and Materials, Conshohocken, PA.

Atabey E. (2009). Türkiye de asbest, eriyonit, kuvars ve diğer mineral tozları ve etkileri. Maden Tetkik ve Arama Müdürlüğü, pp. 188.

Cossette, M., \& Delvaux, P. (1979). “Technical Evaluation of Chrysotile Asbestos Ore Bodies”, Short Course in Mineralogical Techniques of Asbestos Determination. R. L. Ledoux, ed., Mineralogical Association of Canada, pp. 79-110.

Deer, W. A., Howie, R. A. \& Zussman J. (2009). Serpentines, Rock-forming minerals: Layered silicates 
excluding micas and clay minerals, Vol. 3B, John Wiley \& Sons, New York, pp. 157-211. Retrieved from: https://pubs.geoscienceworld.org/canmin/article-abstract/48/5/1319/127220/

Erdoğan, N., \& Yıldız, R., (1995). Magnezit ve Bazik Refrakter Malzeme Teknolojisi, Retrieved from: https://www.researchgate.net/publication/279537853

EU, (1976). Official Journal of the European Union. Council Directive 76/769/EEC of 27 July 1976 on the approximation of the laws, regulations and administrative provisions of the Member States relating to restrictions on the marketing and use of certain dangerous substances and preparations [Accessed 2021 July 21]. Available at: https://eur-lex.europa.eu/legal-content/en/ALL/?uri=CELEX\%3A31976L0769

EU, (1983). Official Journal of the European Union. Council Directive 83/477/EEC of 19 September 1983 on the protection of workers from the risks related to exposure to asbestos at work (second individual Directive within the meaning of Article 8 of Directive 80/1107/EEC) [Accessed 2021 July 21]. Available at:https://eur-lex.europa.eu/legal-content/EN/TXT/?uri=celex\%3A31983L0477

EU, (1991). Official Journal of the European Union. Council Directive 91/383/EEC of 25 June 1991 supplementing the measures to encourage improvements in the safety and health at work of workers with a fixed- duration employment relationship or a temporary employment relationship) [Accessed 2021 July 21]. Available at: https://eur-lex.europa.eu/legalcontent/EN/TXT/?uri=celex\%3A31991L0383

EU, (2003). Official Journal of the European Union. Council Directive 83/477/EEC on the protection of workers from the risks related to exposure to asbestos at work [Accessed 2021 July 21]. Available at: https://eur-lex.europa.eu/legal-content/EN/TXT/?uri=celex\%3A32003L0018

EU, (2006). Official Journal of the European Union Regulation (EC) No 1907/2006 of the European Parliament and of the Council of 18 December 2006 concerning the Registration, Evaluation, Authorisation and Restriction of Chemicals (REACH), establishing a European Chemicals Agency, [Accessed 2021 July 21]. Available at: https://eur-lex.europa.eu/legal-content/EN/TXT/?uri=CELEX\%3A02006R1907$\underline{20140410}$

EU, (2009). Official Journal of the European Union. Council Directive 2009/148/EC of the European Parliament and of the Council of 30 November 2009 on the protection of workers from the risks related to exposure to asbestos at work [Accessed 2021 July 21]. Available at: https://eur-lex.europa.eu/legalcontent/EN/TXT/?uri=celex\%3A32009L0148

ISO 13794, (1999). Ambient Air-Determination of Asbestos Fibres — Indirect-Transfer Transmission Electron Microscopy Method, International Organization for Standardization, Geneva, Switzerland.

ISO 14966, (2002). Ambient Air-Determination of Numerical Concentration of Inorganic Fibrous Particles-Scanning Electron Microscopy Method, International Organization for Standardization, Geneva, Switzerland.

Marioryad, H., Kakooei, H., Shahtaheri, S. J., Yunesian, M., \& Azam, K. (2011). Assessment of airborne asbestos exposure at an asbestos cement sheet and pipe factory in Iran. Regulatory Toxicology and Pharmacology, 60(2), 200-205. DOI: https://doi.org/10.1016/j.yrtph.2011.03.005

Melville, R., \& Lippmann, M. (2001). Influence of data elements in OSHA air sampling database on occupational exposure levels. Applied Occupational and Environmental Hygiene, 16(9), 884-899. DOI: https://doi.org/10.1080/10473220117850

Park, S. H. (2018). Types and health hazards of fibrous materials used as asbestos substitutes. Safety and Health at Work, 9(3), 360-364. DOI: https://doi.org/10.1016/j.shaw.2018.05.001

Rees, D., Phillips, J. I., Garton, E. \& Pooley, F.D. (2001). Asbestos lung fibre concentrations in south African chrysotile mine workers. The Annals of Occupational Hygiene, 45(6), 473-477, DOI: https://doi.org/10.1016/S0003-4878(00)00088-0

Rodilla, J. M. R., Cerrada, B. C., Pujadas, C. S., Delclos, G. L., \& Benavides, F. G. (2021). Fiber burden and asbestos-related diseases: an umbrella review. Gaceta Sanitaria. In Press, DOI: https://doi.org/10.1016/j.gaceta.2021.04.001 
WHO, (2007). World Health Organization, Outline for the development of national programmes for elimination of asbestos-related diseases (No. WHO/SDE/PHE/07.02). World Health Organization.

ZMKKYHY, (2014). Regulation on Restriction and Prohibition of Hazardous Substances and Mixtures, Official GazetteOfficial Journal number 27277 on 03.07.2009, Ankara. Retrieved from: https://www.resmigazete.gov.tr/eskiler/2014/11/20141121-6.htm 